ORIGINAL ARTICLE

\title{
Evaluation of Oral Health Literacy among Adults in Sari - Iran
}

\author{
MARYAM ZAMANZADEH ${ }^{1,2}$, ELHAM MAHMOODNIA ${ }^{3}$, MAHMOOD MOOSAZADEH $^{4}$, ANAHITA GHORBANI $^{2,5}$ \\ ${ }^{1}$ Assistant Professor, Department of Oral and Maxillofacial Pathology, Faculty of Dentistry, Mazandaran University of Medical Sciences, Sari, Iran \\ ${ }^{2}$ Dental Research Center, Mazandaran University of Medical Sciences, Sari, Iran \\ ${ }^{3}$ Oral Health Research Center, Health research institute, Babol University of Medical Science, Babol, I.R. Iran \\ ${ }^{4}$ Gastrointestinal Cancer Research Center, Non-communicable Diseases Institute, Mazandaran University of Medical Sciences, Sari, Iran \\ ${ }^{5}$ Assistant Professor, Department of Oral and Maxillofacial Medicine, Faculty of Dentistry, Mazandaran University of Medical Sciences, Sari, Iran \\ ${ }^{*}$ Corresponding author: Anahita Ghorbani, Assistant Professor, Department of Oral and Maxillofacial Medicine, Faculty of Dentistry, Mazandaran \\ University of Medical Sciences, Sari, Iran. Email: Anahita1802@yahoo.com, Tel: +98 1133244894
}

\begin{abstract}
Background and aim: It is generally accepted that oral health literacy is one of the important determinants of oral health. The aim of this study was to evaluated oral health literacy in Sari City -Northern Iran.

Methods: This cross-sectional study was carried out on 855 adult citizens of Sari by random sampling. The data was collected using a standard questionnaire including 17 questions regarding oral health literacy in four sections: content comprehension, number comprehension, listening and decision making; three questions about oral health behaviors and some questions about self-assessment of oral health status, age, gender and education. Citizens were divided into three groups in terms of oral health literacy: inadequate (0-9), marginal $(10-11)$, and adequate (12-17). The data was analyzed using descriptive and analytical statistics including chisquare, t-test, ANOVA and correlation coefficient in SPSS ver. 20 software.

Results: $43.3 \%$ of the Sari city citizens had adequate oral health literacy. The mean score of oral health literacy was $10.02 \pm 3.4$ out of 17. Oral health literacy was higher among educated and employed people, as well as those with smaller households. Those who reported better oral health behaviors had higher oral health literacy than others $(P$-value $<0.001)$. Also, those who had poor oral health status in compare with two other groups had lower oral health literacy ( $P$-value $<0.001)$.

Conclusion: The oral health literacy of Sari city citizens was marginal. Oral health care providers need to devise the necessary plans to improve the oral health of the community

Key words: Health Literacy, Oral Health Literacy, Oral Health.
\end{abstract}

\section{INTRODUCTION}

Health literacy includes a set of reading, listening, analyzing, and decision making skills, and the ability to use these skills in health situations that do not necessarily refer to the years of schooling or general reading and writing ability ${ }^{1}$. The World Health Organization (WHO) defines health literacy as a cognitive and social skill that determines individuals' motivation and ability to access, understand and use information in ways that lead to their health maintenance and improvement. Also, health literacy is considered not only an individual trait, but also a key determinant of health at the population level [2]. Health literacy is a key to empower people and, in turn, acts as a tool for addressing health inequalities and improves the knowledge and skills of community members. Health literacy plays an important role in community health and some researchers consider it as a stronger predictor of health in compare with age, income, employment status, education level, and race [3].

Adopting from health literacy definition, the most common definition of oral health literacy is the level of individuals ability to acquire, process and understand oral health information and make appropriate oral health decisions. Oral health literacy not only affects oral health but also affects the quality of life of individuals [4]. Also one of the major factors affecting oral and dental diseases in the community is the level of oral health literacy [5].

$\mathrm{OHL}$ research is a thriving domain. The domain is focused on the development of an $\mathrm{OHL}$ instrument and health promotion practice. Strategic cooperation among countries, institutions, authors, and communities is important to encourage further $\mathrm{OHL}$ research and address oral health problems [6].

Evidence suggests that low health literacy leads to adverse health outcomes such as poor general and mental health, and poor quality of life. It also causes that individuals do not take advantage of preventive or therapeutic services provided by healthcare providers or information provided by health organizations to the community and usually face higher risk for diseases and oral problems $[7,8]$. People often come to the dentist when preventive interventions are too late and there is no way but treatment. The lack of timely referrals to the dentist for prevention services is rooted in people's cultural, economic, social and psychological issues [9].

Given that health literacy is directly related with the health of people in the community, then examining it in each country is a necessity. Due to inadequacy of studies conducted in Iran and the cultural and social differences between different cities of Iran and with regard to the importance of oral health literacy in the planning, training and promotion of public health, present study was conducted to assess the level of oral health literacy as a determinant factor of oral health among the citizens of Sari City as the capital of Mazandaran province (Iran).

\section{METHODS}

This cross-sectional descriptive-analytic study was carried out using a questionnaire regarding 18-65 year old adults in Sari city with different social and economic conditions.

Considering an unawareness rate of $80 \%$ in Javadzadeh et al. study [10], a confidence level of $95 \%$ (alpha 0.05), an accuracy of 0.04 and using sample size 
formula, the sample size was determined 400 individuals that according to type of sampling (cluster sampling) it was multiplied by 2 (design effect) and was raised to 800 .

The questionnaires were distributed from February to July 2018. The participants entered the study with discretion and their oral consent was received. The questionnaires were unnamed and remained confidential to the researcher.

The ethical code was IR.MAzUMS.REC.1395.2226.

A multistage sampling method was used for the purpose of the study. First, the city of Sari was divided into 5 regions: Center, West, East, North and South. Each area was considered as a category. According to the estimated sample size, the number of needed clusters was 80 , and in each cluster, 10 individuals were examined. As the population ratios of the regions were equal, equal number of clusters, i.e. 16 clusters, were assigned to each one of the regions. The cluster heads were households covered by each region, selected by systematic random sampling based on the number of households present in the health centers. The examination began from the first household of the cluster and by moving from the right; other households of the cluster were inquired till the sample size of 10 individuals in each cluster was realized. If one or more eligible individuals of a household were not present at the place, they were followed up twice. If the inquiry was not possible after two visits, the individual(s) would be removed and another person(s) would be replaced from the next household. Also, if more than one person of a household was eligible to participate in the study, only one person, the one whose birth date was closer to the date of the survey, was included in the study. Those who couldn't read or write were excluded from the study.

Given the high size of the sample, 4 interviewers, in addition to the researcher, were employed and one region was assigned to each one of these 5 interviewers. In order to unify data collection methods and avoiding different interview procedures, the interviewers were trained in a practical session by the researcher. The interviewer explained the completion of different sections and also conducted an interview regarding listening section, but did not help in understanding the concepts.

The Oral Health Literacy Adult Questionnaire $(\mathrm{OHL}-$ $A Q$ ), a new measurement tool, was used to measure people's health literacy. Validity and reliability of the questionnaire have been reviewed and approved for the Iranian population [11].

The questionnaire includes 17 oral health literacy questions in four parts: reading comprehension, numbers comprehension, listening, decision making; three questions about oral health behaviors; one question about oral and dental health information resources; and one question about self-assessment of oral health status, as well as some questions demographic questions include age, sex, and education.

The "comprehension" section evaluated the reading comprehension and oral health knowledge of the subjects, which included six fill in the blank questions regarding oral health issues including the relationship between oral problems with other diseases, the ways of preventing teeth decay, number of the teeth and the time of their eruption.
The "numbers comprehension" section evaluates reading, writing, and counting skills. This section contains 4 questions that the patient should answer two questions after reading a prescription related to antibiotic consumption and two other questions after reading the instructions of using mouthwash liquid.

The "Listening" section evaluated the listening, reading, writing and counting skills, which included two questions. In this section, an instruction consisting of the points to follow after tooth extraction was read by interviewer twice loudly to the patient, and the patient responded to the questions after hearing them. The "decision-making" section evaluated the reading, comprehension and decision-making skills, which included three questions about how to deal with oral and dental problems (gum bleeding during brushing, pain and swelling in the mouth, the best way to remove dental plaque) and two questions about some concepts in patient case.

Each question had one correct answer, one or more wrong answers and one I do not know answer. The scoring method was so that 1 point was assigned to the correct answers and zero points were assigned to I do not know answers, wrong answers, and unanswered questions. According to the number of questions, the score of the questionnaire was in a range of $0-17$ and the subjects were classified into three; inadequate (0-9), marginal (10-11) and adequate (12-17) groups according to their scores [11].

The questions related to oral hygiene habits included brushing, using toothpaste, and sweet snacks consumption. Also, the oral health self-assessment questions were divided into three groups: good, moderate, and bad.

The data was entered into SPSS Ver. 20 Software. Then, demographic characteristics and level of literacy were analyzed using mean, standard deviation and percentage frequency. Also, Chi-square (Fisher's exact test), T-test, and multiple regression tests were used to analyze the data.

\section{RESULTS}

In sum, 855 individuals took part in the study that 489 $(57.2 \%)$ of them were male and $366(42.8 \%)$ were female. The mean age of participants was $38.4 \pm 13$ years (age range 18-55 years). Eight percent of the participants had high school diploma or less and $82 \%$ of them had higher education (table 1).

Accordingly, $43.3 \%$ of the participants had adequate literacy, $39.6 \%$ had inadequate literacy and $17.1 \%$ had marginal literacy.

The average score of oral health literacy for adults in Sari City was $10.02 \pm 3.4$ with a median of 11 and a minimum score of 1 and a maximum score of 16 . In this study, no statistically significant difference was observed between males and females in terms of oral health literacy (P-value $=0.986)$.

Regarding to the age, no significant difference was observed in the level of literacy between people under and over 30 years old $(P$-value $=0.264)$. Also, people with higher education had higher oral health level ( $P$-value $<0.001$ ). 
In this study, a significant difference was observed between the mean level of literacy and job status, so that the employed individuals had the highest level of education $(10.5 \pm 3.3)$ and retired individuals had the lowest level of education (9.4 \pm 3.6$)$. Also, a reverse relationship was observed between the number of household members and the average level of literacy, so that people from households with more than 4 members had a lower level of literacy than those from a household with 4 or less members. Table 1 shows the mean score of adults' oral health literacy in Sari City regarding demographic and social factors.

In this research, the most correct answers were for the questions of the "Number comprehension" section (82\%), content comprehension (64\%), decision making (46.5\%), and listening (28.7\%), respectively.

Also, regarding the frequency distribution of correct answers regarding each one of the questions, the highest percentage of correct answer was for question 4 (medicine taking time) and the lowest correct answer was for question 13 (the role of dentist in the unwanted outcomes of treatment). The correct response rate for all questions except for question 8 (the time of removing gauze after tooth extraction) showed no statistically significant difference between men and women.

Table 2 shows the frequency distribution of oral health behaviors separately for underlying factors. As it can be seen from above table, people over 30 years of age were more likely to consume sweet snacks ( $P$ value $=0.019)$, brush fewer times $(P$-value $<0.001)$, and also use toothpaste less $(P$-value $<0.001)$ than those under 30 years of age. Those with higher education levels reported more brushing times ( $\mathrm{P}$-value $<0.001)$, more toothpaste consumption $(P$-value $<0.001)$ and less sugar intake $(P$ value $=0.004$ ) compared to those with less education levels.

Most of the participants in the study brushed less than once a day, and women were significantly more likely to brush their teeth $(P$-value $<0.001)$ and use toothpaste ( $P$-value $=0.023$ ). In present study, people with higher oral health literacy had a more favorable behavior regarding brushing, using toothpaste and less sugar intake. Table 3 shows the correlation coefficient of oral health literacy and oral health behaviors.

Also, evaluating the participants in terms of oral health showed that $43.9 \%$ of the subjects reported their oral condition moderate, $25.6 \%$ reported it bad, $21.2 \%$ reported it good and 9.4\% selected "I don't know" choice. Based on one-way ANOVA, there is a correlation between oral health literacy and self-assessment of oral health ( $P$ value $<0.001$ ), so that oral health literacy score was lower in those who had evaluated their oral health status poorer than two other groups.

\section{DISCUSSION}

The present study which was conducted to investigate the oral health literacy of the adults in Sari City showed that adult oral health literacy is marginal in this city and the mean oral health literacy score is 10.02 out of 17 . In this study, people with less than 30 years of old had higher oral health literacy and no significant difference was observed between men and women. Also, a significant relationship was observed between citizens' education and their oral health literacy, so that people with higher education levels had higher oral health literacy.

In the present study, 43.3 percent of citizens with oral health education had adequate oral health education. While in Neqibi et al study in Tehran, $40.5 \%$ of subjects [12] and in Seyed Moallemi et al. study in Isfahan, 53\% of subjects [13] had adequate oral health literacy. Also, in the present study, the mean score of adult oral health literacy was 10.02, while these scores were 10.5 [12] and 11.1 [13] in the studies conducted by Naqibi et al. and Seyed Moallemi et al., respectively.

In a study by Jones et al., the level of oral health literacy in the community was reported inadequate [14], but in a study in Canada, most participants (89\%) had adequate oral health literacy [15].

In another study, Tetani et al. investigated the influence of oral health literacy (OHL) and associated factors on dissatisfaction with oral health $(\mathrm{DOH})$ among older Brazilians. The overall prevalence of $\mathrm{DOH}$ was $21.1 \%$ and they showed that older people with low $\mathrm{OHL}$ were 1.28 times more likely to have $\mathrm{DOH}$ than those with high $\mathrm{OHL}$. Dissatisfaction with oral health in the elderly is a complex issue associated with $\mathrm{OHL}$, social and behavioral factors [16].

In the present study, gender differences had no impact on oral health literacy, which is consistent with the findings of Lee JY in US [17], Sabah et al. in Canada [15] and Haridas in India [18]. Nevertheless, in the study of Seyed Moallemi in Isfahan [13] and Naqibi in Tehran [12], women's health literacy was higher than that of men, and in the Lee KE study in Korea [19]. men's oral health literacy was reported more than women.

In the present study, the oral health literacy of subjects under the age of 30 years was higher than that of older people, which is consistent with the result obtained by Batisa et al. [20]. However, in Jones et al. [14] and Seyed Moallemi [13] studies, the older subjects had higher oral health literacy. The reason may be that in current study the subjects under 30 years of age had higher education levels.

In the present study, like the study of Seyed Moallemi and Naqibi [12,13], there was a significant relationship between education level and health literacy, so that people with higher education had higher oral health literacy; People with higher education may have received oral health information during their school time. On the other hand, these people have a better chance to benefit from educational and counseling programs. In addition, they have a better understanding of the training and the teachings influence them more effectively.

In the present study, 59\% of the subjects reported that they brush their teeth less than once a day and $27 \%$ of them reported that they brush their teeth just once a day. On the contrary, in the studies conducted by Naqibi [12] and Seyed Moallemi [13] $82 \%$ and $77 \%$ of the subjects reported that they brush their teeth once a day, respectively. Also, in studies of adults in China [4] and Burkina Fascio [21], 85\% and 57\% of them were brushing once a day, while in North America, this rate was more than $95 \%$. 
In this study and similar studies [12,22], those who brushed their teeth more frequently had higher oral health literacy, which is consistent with the findings of the study by Batisa et al. [20], in which people who brushed their teeth less than three times a day, or used dental floss on an irregular basis, had lower levels of health literacy. Similarly, in a study by Ueno et al. [23], people with higher health literacy reported that they brush their teeth more frequently and have regular dental visits.

In general, in the present study and similar researches [12] oral health literacy was associated with oral health behaviors, so that the subjects with higher health literate reported better oral health behaviors. Based on behavioral models such as the theory of reasoned action model [24] and health belief model [25], the effect of oral health literacy on oral health behaviors can be considered reasonable. At the same time, one cannot ignore the impact of oral health behaviors on oral health literacy and a mutual relationship can be considered between these two.

In the present study, the highest percentage of correct answers related to the number comprehension section, which was consistent with the results obtained by Seyed Moallemi [13]. In addition, in Naqibi study [12], the highest percentage of correct answers were related to the number comprehension and listening sections. Here, the least correct answers are related to the listening section, which is in agreement with the study of Seyed Moallemi [13]. Therefore, there is a need to repeat the teachings and try to improve the listening skills of the Sari citizens. In addition, the medical staff including the doctors, dentists, and nurses should ensure that people learn and understand the instructions when they provide prescriptions or health instructions.

The present study, as well as the studies conducted by Naqibi [12] and Seyed Moallemi [13] showed that those who had a poor self-assessment of their oral health have also a lower level of oral health literacy. Based on selfefficacy behavioral model [26], low oral health literacy can cause people imagine they are unable to observe their oral hygiene. Also, low oral health literacy, due to its negative impact on health behaviors, leads to a decline in oral health status in terms of clinical indices, and, in fact, due to being aware of oral problems such as having tooth decay, evaluate their status poor.

\section{CONCLUSION}

The results of the study showed that residents of Sari city have inadequate oral health literacy. Oral health literacy was higher in individuals over 30 years of old and people with higher education, and oral health behaviors were also higher in women in compare with men. Given the relative low level of oral health in the study population, the necessity of planning for oral health education in different groups of society and taking advantage of different educational methods seems to be necessary.

Conflict of Interest: There is no conflict of interest to be declared.

Acknowledgment: Present paper is derived from a doctorial thesis with registration number 13949 approved by Mazandaran University of Medical Sciences, and hereby we appreciate the cooperation of all agents.

Funding: Mazandaran University of Medical Sciences Supported us in this project.

Table 1: The mean score of adults' oral health literacy in Sari city in terms of demographic and social factors

\begin{tabular}{|c|c|c|c|}
\hline \multicolumn{2}{|l|}{ Title } & $\begin{array}{l}\text { Mean score }( \pm \\
\text { SD) }\end{array}$ & $P$ value \\
\hline \multirow[t]{2}{*}{ Gender } & Female & $10.02 \pm 3.4$ & \multirow[t]{2}{*}{0.986} \\
\hline & Male & $10.02 \pm 3.4$ & \\
\hline \multirow[t]{2}{*}{ Age } & $\begin{array}{l}\text { Less than } 30 \text { years } \\
\text { old }\end{array}$ & $10.2 \pm 3.3$ & \multirow[t]{2}{*}{0.264} \\
\hline & $\begin{array}{l}\text { More than } 30 \text { years } \\
\text { old }\end{array}$ & $9.92 \pm 3.4$ & \\
\hline \multirow[t]{3}{*}{ Education } & $\begin{array}{l}\text { Less than high school } \\
\text { diploma }\end{array}$ & $7.4 \pm 3.9$ & \multirow[t]{3}{*}{$<0.001$} \\
\hline & Diploma & $9.1 \pm 3.7$ & \\
\hline & Higher Education & $10.4 \pm 3.2$ & \\
\hline \multirow[t]{5}{*}{ Job status } & Housewife & $9.5 \pm 3.5$ & \multirow[t]{5}{*}{0.002} \\
\hline & Student & $9.7 \pm 3.5$ & \\
\hline & Employed & $10.5 \pm 3.3$ & \\
\hline & Unemployed & $10.2 \pm 3.2$ & \\
\hline & Retired & $9.4 \pm 3.6$ & \\
\hline \multirow[t]{2}{*}{$\begin{array}{l}\text { Household } \\
\text { size }\end{array}$} & $\begin{array}{l}\text { Less or equal } 4 \\
\text { members }\end{array}$ & $10.4 \pm 3.3$ & \multirow[t]{2}{*}{$<0.001$} \\
\hline & More than 4 members & $9.5 \pm 3.5$ & \\
\hline
\end{tabular}

Table 2: Frequency distribution percentage for oral health behaviors in adults in Sari city in terms of age, sex, education

\begin{tabular}{|c|c|c|c|c|c|c|c|c|c|c|c|}
\hline \multirow{2}{*}{$\begin{array}{l}\text { Oral Health } \\
\text { Behaviors }\end{array}$} & \multicolumn{3}{|l|}{ Age } & \multicolumn{3}{|l|}{ Gender } & \multicolumn{4}{|l|}{ education } & \multirow[t]{2}{*}{ Total } \\
\hline & $\begin{array}{l}\text { Less } \\
\text { than } 30\end{array}$ & $\begin{array}{l}\text { More } \\
\text { than } 30\end{array}$ & $\mathrm{P}$ & Female & Male & $P$ & $\begin{array}{l}\text { Less than } \\
\text { diploma }\end{array}$ & Diploma & $\begin{array}{l}\text { Higher } \\
\text { Education }\end{array}$ & $P$ value & \\
\hline \multicolumn{12}{|l|}{$\begin{array}{l}\text { Frequency of } \\
\text { brushing in a } \\
\text { day }\end{array}$} \\
\hline $\begin{array}{l}\text { Less than once } \\
\text { a day }\end{array}$ & 43.7 & 66.5 & \multirow[t]{3}{*}{$<0.001$} & 50.5 & 65.4 & \multirow[t]{3}{*}{$<0.001$} & 91.3 & 69.1 & 54.8 & \multirow[t]{3}{*}{$<0.001$} & 59 \\
\hline Twice a day & 33 & 24 & & 30.3 & 24.3 & & 8.7 & 21 & 29.4 & & 27 \\
\hline Twice or more & 23.3 & 9.5 & & 19.1 & 10.2 & & 0 & 9.9 & 15.9 & & 14 \\
\hline \multicolumn{12}{|l|}{$\begin{array}{l}\text { Using } \\
\text { toothpaste }^{1}\end{array}$} \\
\hline $\begin{array}{l}\text { Undesirable } \\
\text { behavior }\end{array}$ & 19.4 & 33.2 & \multirow[t]{2}{*}{$<0.001$} & 24.6 & 31.7 & \multirow[t]{2}{*}{0.0230} & 53.6 & 44.4 & 24.4 & \multirow[t]{2}{*}{$<0.001$} & 28.6 \\
\hline $\begin{array}{l}\text { Desirable } \\
\text { behavior }\end{array}$ & 80.6 & 66.8 & & 75.4 & 68.3 & & 46.4 & 55.6 & 57.6 & & 71.4 \\
\hline \multicolumn{12}{|l|}{$\begin{array}{l}\text { Sweet snacks } \\
\text { consumption }^{2}\end{array}$} \\
\hline $\begin{array}{l}\text { Undesirable } \\
\text { behavior }\end{array}$ & $52 \%$ & 60.4 & \multirow{2}{*}{0.019} & 58.7 & 56.9 & \multirow[t]{2}{*}{0.579} & 76.8 & 55.6 & 56 & \multirow[t]{2}{*}{0.004} & 57.6 \\
\hline $\begin{array}{l}\text { Desirable } \\
\text { behavior }\end{array}$ & $48 \%$ & 39.6 & & 41.3 & 43.1 & & 23.2 & 44.4 & 44 & & 42.4 \\
\hline
\end{tabular}

Undesirable behavior: (rarely, never), desirable behavior (always, often)

${ }^{2}$ Undesirable behavior: (three time a day or more, two times a day), desirable behavior (once a day, sometimes, not every day, rarely) 
Table 3: Correlation coefficient of oral health literacy and oral health behaviors

\begin{tabular}{|l|l|l|}
\hline Oral Health Behavior & Oral Health literacy & $\mathrm{P}$ value \\
\hline Frequency of brushing & $\mathrm{R}^{\star}=0.39$ & $<0.001$ \\
\hline Using toothpaste & $\mathrm{R}=0.29$ & $<0.001$ \\
\hline $\begin{array}{l}\text { Frequency of sweet snacks } \\
\text { consumption }\end{array}$ & $\mathrm{R}=0.13$ & $<0.001$ \\
\hline
\end{tabular}

${ }^{\text {* } \mathrm{R}=\text { Correlation coefficient }}$

\section{REFERENCES}

1. Saranjit S, Lennard L. Health literacy: being able to make the most of health: National Consumer Council; 2004.

2. Marmot M, Friel S, Bell R, Houweling TA, Taylor S. Closing the gap in a generation: health equity through action on the social determinants of health. Lancet (London, $\quad$ England). 2008;372(9650):1661-9. doi.10.1016/s0140-6736(08)61690-6.

3. Adams RJ, Stocks NP, Wilson DH, Hill CL, Gravier S, Kickbusch I, Beilby JJ. Health literacy--a new concept for general practice? Australian family physician 2009;38(3):144-7.

4. Isman B. Healthy People 2010: Oral Health Toolkit. National Institute of Dental and Craniofacial Research (NIDCR). 2007.

5. Buunk-Werkhoven YA, Dijkstra A, van der Schans CP Determinants of oral hygiene behavior: a study based on the theory of planned behavior. Community dentistry and oral epidemiology. 2011;39(3):250-9. doi.10.1111/j.16000528.2010.00589.x.

6. Sun Y, Li C, Zhao Y, Sun J. Trends and developments in oral health literacy: a scientometric research study (1991-2020). BDJ Open. 2021;7(13). https://doi.org/10.1038/s41405-021-00066-5

7. Horowitz AM, Kleinman DV. Oral health literacy: a pathway to reducing oral health disparities in Maryland. Journal of public health dentistry. 2012;72 Suppl 1:S2630. doi.10.1111/j.1752-7325.2012.00316.x.

8. Burt BA, Eklund SA. Dentistry, dental practice, and the community-E-book: Elsevier Health Sciences; 2005.

9. Horowitz AM, Kleinman DV. Oral health literacy: the new imperative to better oral health. Dental clinics of North America. 2008;52(2):333-44, doi.10.1016/j.cden.2007.12.001

10. Javadzade SH, Sharifirad G, Radjati F, Mostafavi F, Reisi M, Hasanzade A. Relationship between health literacy, health status, and healthy behaviors among older adults in Isfahan, Iran. Journal of education and health promotion. 2012;1:31. doi.10.4103/22779531.100160.

11. Naghibi Sistani MM, Yazdani R, Virtanen J, Pakdaman A, Murtomaa $\mathrm{H}$. Determinants of oral health: does oral health literacy matter? ISRN dentistry. 2013;2013:249591. doi.10.1155/2013/249591.

12. Sistani MM, Yazdani $R$, Virtanen J, Pakdaman $A$, Murtomaa $\mathrm{H}$. Oral health literacy and information sources among adults in Tehran, Iran. Community dental health. 2013;30(3):178-82.
13. Moallemi S, Haghighi M. Assessing oral health literacy among the residents of Isfahan in 2014-2015. J Isfahan Dent Sch. 2016; 12(3): 268-279.

14. Jones M, Lee JY, Rozier RG. Oral health literacy among adult patients seeking dental care. Journal of the American Dental Association (1939). 2007;138(9):1199208; quiz 266-7. doi.10.14219/jada.archive.2007.0344.

15. Sabbah W, Tsakos G, Chandola T, Sheiham A, Watt $R G$. Social gradients in oral and general health. Journal of dental research. 2007;86(10):992-6. doi.10.1177/154405910708601014

16. Tenani, CF, De Checchi, MHR, Bado, FMR, Ju, $X$, Jamieson, L, Mialhe, FL. Influence of oral health literacy on dissatisfaction with oral health among older people. Gerodontology. 2020; 37: 4652. https://doi.org/10.1111/ger.12443

17. Lee JY, Divaris K, Baker AD, Rozier RG, Lee SY, Vann WF, Jr. Oral health literacy levels among a low-income WIC population. Journal of public health dentistry. 2011;71(2):152-60. 7325.2011.00244.x. doi.10.1111/j.1752-

. Haridas R, S S, Ajagannanavar SL, Tikare S, Maliyil MJ, Kalappa AA. Oral Health Literacy and Oral Health Status among Adults Attending Dental College Hospital in India. Journal of international oral health : JIOH. 2014;6(6):61-

19. Lee KE, Yom Y-H, Kim SS, Han JH. Gender differences in oral health literacy related factors among elderly people. Journal of Korean Academy of Community Health Nursing. 2014; 25(1):54-64.

20. Batista MJ, Lawrence HP, Sousa M. Oral health literacy and oral health outcomes in an adult population in Brazil. BMC public health. 2017;18(1):60. doi.10.1186/s12889017-4443-0.

21. Varenne B, Petersen PE, Ouattara S. Oral health behaviour of children and adults in urban and rural areas of Burkina Faso, Africa. International dental journal. 2006;56(2):61-70. 595x.2006.tb00075.x.

22. Parker EJ, Jamieson LM. Associations between indigenous Australian oral health literacy and selfreported oral health outcomes. BMC oral health. 2010;10:3. doi.10.1186/1472-6831-10-3.

23. Ueno M, Takeuchi S, Oshiro A, Kawaguchi Y. Relationship between oral health literacy and oral health behaviors and clinical status in Japanese adults. Journal of Dental Sciences. 2013;8(2):170-6.

24. Syrjälä AM, Niskanen MC, Knuuttila ML. The theory of reasoned action in describing tooth brushing, dental caries and diabetes adherence among diabetic patients. Journal of clinical periodontology. 2002;29(5):427-32. doi.10.1034/j.1600-051x.2002.290507.x.

25. Hollister MC, Anema MG. Health behavior models and oral health: a review. Journal of dental hygiene : JDH. 2004;78(3):6.

26. Bandura A. Self-efficacy: toward a unifying theory of behavioral change. Psychological review. 1977;84(2):191-215. doi.10.1037//0033-295x.84.2.191. 